\title{
Personalidade e risco: uma análise dos processos de tomada de decisão à luz das finanças comportamentais
}

\section{Personality and risk: an analysis of decision-making processes in the light of behavioral finance}

\author{
THIAGO DE SOUSA BARROS \\ ANDRÉ STEFANO FUJIWARA
}

\section{RESUMO}

Em economia, quando se trata da tomada de decisão dos agentes econômicos sobre o risco, tem-se como base principal a Teoria da Utilidade. Porém, novos estudos em finanças comportamentais tem sido motivo de grande discussão, pois evidenciam que os indivíduos sofrem de vieses no processo decisório, fazendo com que as decisões nem sempre tendem a otimização. Assim, este estudo tende a contribuir com este tema por meio de uma pesquisa realizada entre 2018 e 2019, que analisou 211 estudantes de graduação e pós-graduação, nos estados de Minas Gerais e São Paulo, levando em consideração a relação entre os traços de personalidade e vieses comportamentais. Os resultados obtidos na pesquisa demonstram que dois traços de personalidade (extroversão e abertura) têm relação positiva com vieses de enquadramento e concepções errôneas de probabilidade. Ademais, observa-se também uma relação positiva e significante do traço de personalidade de estabilidade com o viés de 'concepções errôneas de probabilidade'. Outra evidência importante deste artigo é que o grau de instrução dos indivíduos não tem relação com a ocorrência dos eventos, indicando que estes ocorrem independentemente do nível de estudos dos respondentes. Em sum, 
tais resultados enfatizam a importância de estudar este tema por uma nova ótica econômica, como é o caso das finanças comportamentais, trazendo contribuições para o entendimento da tomada de decisão dos agentes, evidenciando como suas características pessoais e de personalidade interferem nesse processo.

Palavras-chave: Teoria do Prospecto, finanças comportamentais, personalidade, risco, tomada de decisão.

\section{Abstract}

In economics, when it comes to the decision making of economic agents about risk, the Theory of Utility is the main basis. However, new studies in behavioral finance have been the subject of much discussion, as they show that individuals suffer from bias in the decision-making process, making decisions not always tend to be optimized. Thus, this study tends to contribute to this theme through a research carried out between 2018 and 2019, which analyzed 211 undergraduate and graduate students, in the states of Minas Gerais and São Paulo, taking into account the relationship between the traits of personality and behavioral biases. The results obtained in the research demonstrate that two personality traits (extroversion and openness) have a positive relationship with framing biases and misconceptions of probability. Furthermore, there is also a positive and significant relationship between the personality trait of stability and the 'misconceptions of probability' bias. Another important evidence of this article is that the individuals 'level of education is not related to the occurrence of events, indicating that they occur regardless of the respondents' level of education. In sum, such results emphasize the importance of studying this topic from a new economic perspective, as is the case with behavioral finance, bringing contributions to the understanding of the agents' decision making, showing how their personal and personality characteristics interfere in this process.

Keywords: Prospect Theory, behavioral finance, personality, risk, decision making. 


\section{INTRODUÇÃo}

Estudos recentes em finanças e economia buscam compreender como acontecem os processos de tomada de decisão dos agentes econômicos, se estas são apresentadas à margem da racionalidade, contemplam todas as informações disponíveis, e como se dá o funcionamento dos mercados financeiros (STOSIC-MIHAJLOVIC, 2016; LEGESSE; GUO, 2020; VARDARI, 2020), aspectos explorados à exaustão pela Moderna Teoria das Carteiras de Markowitz (1952), bem como pela Hipótese dos Mercados Eficientes de Fama (1970).

Todavia, surgem os trabalhos de Tversky e Kahneman (1974 e 1979), marcos para o surgimento das finanças comportamentais, uma vez que os autores mostraram que a tomada de decisão dos indivíduos apresenta vieses, dado que os agentes possuem diferentes capacidades cognitivas e tomam decisões fazendo uso de atalhos mentais devido à racionalidade limitada. Desde a publicação desse trabalho seminal, outros estudos foram realizados com resultados que reforçam estas primeiras descobertas, trazendo colaborações para melhor entendimento dos diversos fenômenos econômicos (BARROS; FELIPE, 2015; BALDO; KNUPP, 2018; ANTONY, 2019; ANI; ÖZARI, 2020; BRENNER; MEYLL, 2020; SHERIF, 2020; KÖNIGSTORFER; THALMANN, 2020; VENDRAMINE; NOBRE; VIEIRA, 2021).

Desse modo, as finanças comportamentais constituem, na atualidade, uma área de conhecimento vasto, reunindo campos da psicologia, economia, matemática e estatística, tendo como principal objetivo analisar as escolhas feitas pelos indivíduos, o que permite descrever e explicar tais decisões, sendo, portanto, um contraponto aos clássicos modelos de finanças (FRANCESCHINI, 2015).

Para entender melhor como ocorre à tomada de decisão dos indivíduos, algumas ferramentas foram desenvolvidas para este fim. Ante tal evidência, o centro deste estudo tangencia a percepção de Personalidade e Risco. Em linhas gerais, conforme já observado pela teoria, pode-se partir do pressuposto que a decisão do agente econômico não está ligada somente a sua tolerância ao risco e seu medo de que os retornos de sua decisão tenham um peso negativo, mas também a características como sua personalidade, sexo, faixa etária, escolaridade, estado civil, renda, localização geográfica, entre outras (ÁVILA et al., 2016). 
Assim, embasado em tais parâmetros, este artigo tenciona responder a seguinte questão: os diversos tipos de personalidade afetam o grau de tolerância ao risco no processo de tomada de decisão financeira? Se sim, quais as variáveis independentes que tendem a ter maior impacto sobre os indivíduos? Em suma, pretende-se analisar se os agentes deixam de ser racionais em determinantes circunstâncias e tendem ao erro, e como racionalizar e precipitar tais decisões, tendo por base os dados coletados nesta pesquisa.

Os resultados obtidos neste artigo proporcionam melhor entendimento de como a personalidade do agente pode interferir na tomada de decisão, o que possibilita prever tal comportamento a fim de melhorar o processo de tomada de decisão, diminuindo, portanto, erros em esferas sociais e econômicas. Nota-se que o tema está em voga na contemporaneidade e é de grande relevância para o meio acadêmico, os mercados financeiros e a sociedade de forma geral.

\section{FINANÇAS COMPORTAMENTAIS: ASPECTOS FUNDAMENTAIS}

As finanças comportamentais têm por base várias abordagens com o objetivo de contrapor as finanças tradicionais, até então amparadas em modelos como o de Precificação de Ativos Financeiros (CAPM) e postulados como a Hipótese de Mercados Eficientes. Estas teorias clássicas das finanças têm seu escopo nos modelos neoclássicos onde se maximiza sua utilidade escolhendo, a cada momento, as melhores alternativas que se lhe apresentam. Coube a Keynes (1936) demonstrar, tal como observado por Shefrin (2015), que a tomada de decisão dos agentes é baseada em grande parte por fatores não racionais, tendo como base sua Teoria Geral onde a importância dos fatores psicológicos não se restringe aos mercados financeiros (animals spirits).

Dessa feita, a Teoria de Finanças Comportamentais ganha espaço quando começam a surgir novas teorias sobre como os agentes tomam suas decisões ainda na década de 1970, sendo muito utilizada para contrapor a Hipótese dos Mercados Eficientes, que trata todos os agentes como racionais e capazes de digerir todas as informações disponíveis, sendo assim racionais o tempo todo (GALDÃO; FAMÁ, 1998). 
Vários estudos começam a tomar forma por volta dos anos de 1980, e têm por objetivo questionar a verificação da eficiência de tais mercados, nascendo a corrente comportamental que tenta então encontrar explicações para a aparente ineficiência dos mercados (ANTONY, 2019; ANI; ÖZARI, 2020). Lobão (2012) define, no que diz respeito às finanças racionais, que há três argumentos principais defendidos pelos pesquisadores da área: i) os investidores com racionalidade limitada podem não ter impacto nos preços se os desvios das suas decisões face ao investidor racional forem aleatórias, ou seja, os agentes agem erroneamente por defeito como por excesso, seu impacto no mercado de eficiência será nulo; ii) os investidores com racionalidade limitada interagem com outros agentes, chamados de árbitros, que tem por pressuposto seguir os preceitos de racionalidade completa, sendo então responsáveis por prever e corrigir possíveis falhas de mercado, porém mesmo corrigindo tais falhas, o agente com racionalidade limitada ainda teria como consequência perdas, e a longo prazo, sua ausência dos mercados. iii) seria sobre a aprendizagem dos investidores. Defendendo então que os investidores até podem apresentar, num primeiro momento, a característica da racionalidade limitada, mas terão incentivos para aprenderem, ao longo do tempo, a ter comportamentos em consonância com a racionalidade completa, fazendo com que, no longo prazo, os preços tendam ao equilíbrio como proposto nos modelos racionais.

Contudo, as Finanças Comportamentais que rebatem tais premissas: i) no primeiro caso, acredita-se que os investidores possam afastar os preços das situações de eficiência, porém, para finanças comportamentais, isso só seria possível dado a viesses cognitivos que então passam a ser sistemáticos e não aleatórios como se acredita. ii) defende-se que os árbitros sofrem restrições em sua atuação ou até que podem ter interesse em não corrigir os erros cometidos pelos agentes com racionalidade limitada, fazendo assim com que aqueles investidores influenciem os mercados financeiros. iii) $\mathrm{O}$ que precisa ser respondido seria se os investidores podem aprender a ser totalmente racionais. A origem das limitações à racionalidade é cognitiva e emocional, desse modo, no começo parece difícil que a aprendizagem garanta a convergência das decisões observadas 
dos investidores para as ditadas pelo paradigma da racionalidade completa (CORTES, 2009; LOBÃO, 2012; BARROS; FELIPE, 2015).

Sob esse enfoque, como bem afirma Krugman (2009), os economistas terão que admitir a importância da irracionalidade das ações não otimizadoras e dos comportamentos imprevisíveis dos indivíduos que fazem com que esse seja mais um tema de uma ciência social. Nessa vertente, a base de estudos das Finanças Comportamentais incide em mostrar como as emoções, o psicológico dos agentes e os erros cognitivos podem influenciar o processo de tomada de decisão de investidores e fazendo então com que esses comportamentos possam determinar mudanças no mercado (HALFELD; TORRES, 2001; KIMURA, 2002).

\subsection{A Teoria do Prospecto}

A Teoria da Perspectiva ou Teoria do Prospecto, tida como a teoria percursora dessa grande área comportamental, foi desenvolvida pelos pesquisadores Kahneman e Tversky (1979), que analisavam principalmente o comportamento dos investidores, tendo assim o argumento de que fatores psicológicos interferiam no processo de tomada de decisão dos agentes, principalmente pela dificuldade em entender tanta informação, afirmando então que não seria possível que todos os agentes fossem racionais e avessos ao risco em todas as suas decisões.

Mineto (2005) defende então que essa teoria é a principal referência em qualquer modelo que pretenda conhecer a determinação dos preços dos ativos, além do comportamento dos investidores, dadas suas preferências e como eles avaliam o risco.

A Teoria da Utilidade Esperada, como asseguram Kahneman e Tversky (1979), não descreve com perfeição como os agentes avaliam as opções de escolha em condições de risco, especialmente quando se fala em escolhas que envolvam perdas. Os autores criticam a Teoria da Utilidade Esperada como um modelo normativo de escolha racional e um modelo descritivo de tomada de decisão sob risco e apresenta um modelo alternativo a essa teoria, chamado de Teoria do Prospecto. Isso acontece em virtude de a função valor na Teoria do Prospecto possuir a forma de S, sendo côncava acima do ponto de referencia e convexa abaixo dele. 
Figura 1 - Função Valor na Teoria do Prospecto

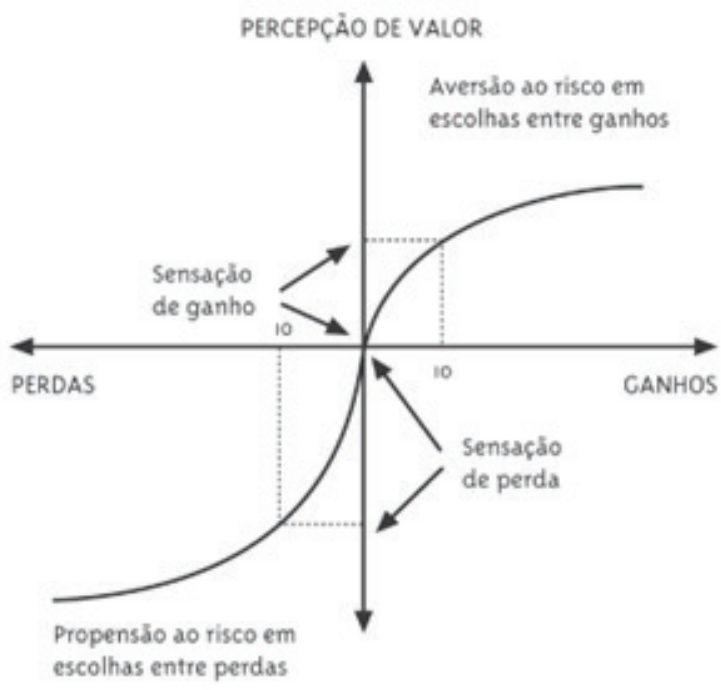

Fonte: Adaptado de Kahneman e Tversky (1979)

Dessa feita, Kahneman e Tversky (1979), por meio da teoria do prospecto, mostram a principal explicação psicológica para o efeito disposição, segundo a qual os ganhos e perdas são julgados frequentemente em analogia a um ponto de referência e os indivíduos apresentam um comportamento de aversão ao risco para ganhos e propensão ao risco para perdas. Assim, se os indivíduos não se adaptam as mudanças de preços e usam o preço de compra de uma ação como uma referência, a decisão de vender uma ação que aumentou desde a compra será vista como uma escolha entre uma certeza de ganho e um risco de ganho.

Dentre todas as teorias que se contradizem à Teoria da Utilidade, a Teoria do Prospecto é a que melhor se encaixa nos modelos financeiros, provavelmente por que é a mais eficiente ao capturar resultados experimentais (BARBERIS; THALER, 2003). No Quadro 1 abaixo estão dispostas, de forma comparada, as principais discrepâncias entre a teoria do prospecto e a teoria da utilidade esperada. 


\section{Quadro 1: Principais Diferenças entre a Teoria da Utilidade Esperada e a Teoria do Prospecto}

\begin{tabular}{|c|c|}
\hline Teoria do Prospecto & Teoria da Utilidade Esperada \\
\hline Economia Comportamental & Economia Neoclássica \\
\hline $\begin{array}{l}\text { Os agentes não conseguem processar todas as } \\
\text { informações devidamente }\end{array}$ & Racionalidade ilimitada dos agentes \\
\hline $\begin{array}{l}\text { Escolhas baseadas nas preferências e também } \\
\text { por aspectos emocionais }\end{array}$ & $\begin{array}{l}\text { Maximização da utilidade através de uma análi- } \\
\text { se risco versus retorno }\end{array}$ \\
\hline $\begin{array}{l}\text { Informação assimétrica, escolhas simples e } \\
\text { emocionais tendem a fazer o mercado não } \\
\text { entrar em equilíbrio }\end{array}$ & $\begin{array}{l}\text { Informação igualitária entre os agentes e os erros } \\
\text { aleatórios que são absorvidos pelo mercado }\end{array}$ \\
\hline $\begin{array}{l}\text { Os agentes tratam as perdas e ganhos de ma- } \\
\text { neira diferente. Quando existe a possibilidade } \\
\text { de perda os agentes buscam maior risco. No } \\
\text { entanto, no campo dos ganhos, os agentes são } \\
\text { avessos ao risco. }\end{array}$ & Perdas e ganhos são tratados da mesma forma \\
\hline $\begin{array}{l}\text { Escolha baseada em duas fases: edição e } \\
\text { avaliação. }\end{array}$ & $\begin{array}{l}\text { Escolha do maior valor esperado } \\
\text { (probabilidade x prêmio) }\end{array}$ \\
\hline $\begin{array}{c}\text { A maioria dos agentes sabe diferenciar pro- } \\
\text { babilidades em relação à certeza. No entanto, } \\
\text { avaliam as probabilidades de maneira diferente } \\
\text { quando estão no campo dos ganhos e das } \\
\text { perdas. }\end{array}$ & $\begin{array}{l}\text { Os agentes sabem avaliar completamente as } \\
\text { probabilidades envolvidas num investimento }\end{array}$ \\
\hline
\end{tabular}

Fonte: Adaptado de Zambonetti, 2009, p.188.

Bazerman (2004) conclui que este estudo contribuiu sobremaneira para uma melhor percepção dos tipos de erros existentes nas decisões de cada indivíduo, assim os pesquisadores da área chegam a conclusão do quão importante é compreender o processo de decisão.

\subsection{Desdobramentos da teoria moderna em finanças com- portamentais}

As áreas de administração, finanças e seguros foram aquelas que mais se utilizam das bases erigidas pela teoria do prospecto. Schrand e Zechman (2012) observaram entre os anos de 1990 e 2000 
executivos de empresas americanas, percebendo a existência de um viés otimista e sendo não intencional. Assim, quando precisavam gerenciar rendimentos crescentes, o excesso de confiança poderia ser o início para distorções intencionais.

Em seguida, Levy e Wiener (2013) observaram uma reação excessiva dos agentes em relação ao preço das ações, foi então que Barberis et al. (2014) verificaram que os investidores menos sofisticados levam em conta o comportamento dos retornos das ações no passado para tomar suas decisões e os investidores mais sofisticados procuram realizar projeções com dos retornos das ações.

É tido que os investidores têm racionalidade limitada, e estão sujeitos a emoções. Aqui é importante esclarecer que as Finanças Comportamentais não negam que a maioria das decisões econômicas é tomada de forma racional e deliberada. Os estudos apenas consideram que, se não forem levadas em conta também as decisões emocionais e automáticas, os modelos econômicos falharam em explicar o funcionamento dos mercados (NUNES, 2017).

Nesta ótica, Ávila et al. (2016) mostraram que, após Tversky e Khaneman (1974), as finanças comportamentais tiveram um aumento significativo em questões de contribuição para a literatura como pesquisa, demonstrado então como os impactos de influencias familiares, crenças, emoções, confiança, amizade, sexo, cultura, percepções de perda e risco, entre outros, podem levar o decisor a ter seu julgamento afetado e podendo ser levado a avaliações erradas e prejudiciais para os tomadores de decisão, fazendo então com que os achados científicos sejam suficientes para levar a quebra do paradigma das hipóteses de eficiência de mercado.

Os limites da racionalidade derivam do ambiente em que o mesmo está inserido tanto quanto de suas características, somando-se, assim: limites cognitivos dos indivíduos que tem sempre uma capacidade limitada de recolher, processar e interpretar informações; a complexidade do problema decisório com qual o agente relevante se defronta, resultante desse atuar em um ambiente cujas relações causais e regularidades são difíceis de serem discernidas; a incerteza em relação a eventos exógenos (PONDÉ, 2014).

Em face disso, Pondé (2014) defende que os procedimentos racionais de decisão não podem estar desconectados do âmbito 
social de que se faz parte, dado que a tomada de decisão envolve uma série de critérios para a avaliação e escolha de alguma alternativa, onde a mesma evolui no processo histórico, pois o decisor é afetado pela interação entre suas decisões e resultados. Nota-se, portanto, que a interferência da emoção é um fator encontrado tanto na percepção quanto na decisão que envolve risco. Aqui vemos o risco como sentimento aliado ao efeito priming que dá sustento teórico para a interferência da emoção na percepção, e sugerindo que a emoção positiva leva o agente a avaliar positivamente uma tomada de decisão e vice-versa.

\section{RISCO E PERSONALIDADE}

De acordo com Bernstein (1997) a capacidade de administrar o risco, e com ele a vontade de correr riscos e de fazer opções ousadas, são elementos-chave da energia que impulsiona o sistema econômico. Ademais, conforme Gitman (1987), risco pode ser definido como a possibilidade de perda ou quando o tomador de decisão pode estimar as probabilidades relativas a vários resultados.

Avançando nesta seara, Cassarrotto (1994) completa a definição de Gitman (1987) e afirma que quando se trabalha com pouca informação ou então na condição de incerteza pode-se utilizar de uma análise de sensibilidade ou simulação para assim poder tomar a decisão mais racional. No trabalho de Snelbecker, Roszkowski e Cutler (1990), um dos fatores mais importantes que interferem nas decisões financeiras é a tolerância ao risco. Nesse diapasão, percebe-se que muitos autores entendem tolerância ao risco como a quantidade máxima de incerteza que o indivíduo está disposto a aceitar ao enfrentar o processo de decisão (TOUBIA et al., 2013).

A tolerância ao risco tende a ser medida e avaliada por meio de um dos cinco métodos: (a) julgamento pessoal ou profissional, (b) heurísticas, (c) questões de um único item, (d) escalas de risco e (e) medidas mistas. Há também utilização de escalas para mensurar o risco, como destacado por Xiao (2008), indo das mais tradicionais como Grable e Joo (2004) e Jackson Personality (Jackson, 1976), até a escala tipo likert de Weber e Betz (2002).

Segundo Halfeld (2001) para definir o perfil de cada investidor é necessário considerar como fator principal a tolerância ao risco. Existem pessoas que estão propensas a maiores riscos para obter 
maiores resultados, tendendo a reagir melhor às flutuações do mercado. Assim sendo, um elemento importante para definir o perfil do investidor é conhecer o objetivo do mesmo, pois para o investidor obter um aumento de capital no longo prazo, o mercado de ações parece como um investimento de baixo risco e um investimento em renda fixa de alto risco. Enquanto que para um investidor com o propósito de preservar seu capital no curto prazo, o mercado de ações parece como um risco alto, dada a volatilidade, e um investimento em renda fixa como um baixo risco, mesmo com baixo retorno.

Neste contexto, Gonçalves, Lima e Matesco (2008) definem custo de oportunidade como uma escolha ótima que resulta na seleção da melhor entre as opções possíveis. Um agente econômico precisa escolher e, quando toma a decisão ótima, não se arrepende, pois não deixou passar nenhuma oportunidade de estar satisfeito ou obter um ganho maior. Assim, feita a escolha correta do investimento, Halfeld (2005) sugere a criação de objetivos bem definidos e fortes incentivos para alcançá-los.

Dadas estas questões, o comportamento humano passou a ser objeto de pesquisas tanto para o meio acadêmico, quanto para área de saúde e o mundo dos negócios, permitindo melhor compreensão do processo de tomada de decisão. Edwards (1945) já sinalizava que pesquisas na área do comportamento humano já eram desenvolvidas por economistas, cientistas, matemáticos e filósofos. Destarte, na década de 1990, ocorre a consolidação desta área de investigação, já que explicava modelos vindo da economia, psicologia social e cognitiva, estatística e outras ciências (PAYNE, BETTMAN E JOHNSON, 1992).

É importante notar que, além da tomada de decisão ser influenciada por valor e expectativas das pessoas (preferências), a maneira como as mesmas são apresentadas, sendo com palavras ou números, causam um impacto considerável no processo decisório conduzindo a diferentes decisões (TVERSKY; KAHNEMAN, 1986).

Nesta ótica, o afeto vem se tornado um aspecto importante e tem sido considerado cada vez mais por pesquisadores como Zajonc (1980), que observou que todas as decisões e percepções tem algum grau de afeto e cognição. De acordo com Borghans et al. (2008) deve-se considerar os aspectos da personalidade do indivíduo para os estudos em economia, mostrando uma maior importância dos mesmos, tendo como taxonomia principal aceita para a definição de per- 
sonalidade aquela descrita no modelo do "Big-Five Personality Trails".

\subsection{Big Five: 0 Modelo de Personalidade}

Este modelo tem origem em Alport e Odbert (1936), onde certas palavras e adjetivos definem a personalidade do indivíduo. Posteriormente, o modelo foi aprimorado por Goldeberg (1971), concluindo que os traços de personalidade podem ser divididos em cinco fatores, a saber (BORGHANS et al., 2008):

- Abertura/Vontade de aprender: é a dimensão em que o indivíduo necessita de estímulos intelectuais, mudança e variedade. Os traços observados são: valores, ideias, sentimentos, ações e fantasia.

- Conscientização: é a dimensão onde a pessoa está disposta a seguir regras, padrões e normas convencionais. Os traços observados são: senso de dever, ordem, esforço pessoal, competência e autodisciplina.

- Extroversão: dimensão onde as pessoas necessitam de interação social e atenção. Os traços observados aqui são: socialização, emoções positivas/negativas, cordialidade, excitação e assertividade.

- Socialização: é a dimensão em que o indivíduo necessita ser agradável e harmonioso em suas relações sociais. Os traços observados são: confiança, fraqueza/simplicidade, altruísmo, credibilidade, consciência crítica.

- Estabilidade: dimensão onde o indivíduo vivência o mundo como um ambiente ameaçador e fora de seu controle. Os traços observados são: ansiedade, depressão, autocontrole, impulsividade, raiva e vulnerabilidade.

Deste modo, foram criados instrumentos para captar e identificar as mais diferentes personalidades, onde perguntas são feitas para os indivíduos, permitindo uma medição diferenciada para cada fator do Big-Five, classificando cada um como uma personalidade e perfil (RAMMSTEDT, 2007).

O BFI-10 é um teste que possui 10 itens, sendo eles dois de cada fator do Big-Five, e escolhidos considerando 5 critérios diferentes, possui frases curtas e diretas onde cada questão deve ser avaliada 
em uma escala que varia entre "discordo totalmente" e "concordo fortemente". Sendo então possível mensurar um perfil em cada um dos cinco fatores de personalidade, fazendo com que o indivíduo estará em uma escala onde um traço de personalidade se torne mais evidente do que outros. Então os indivíduos são classificados em cada fator de personalidade com características de alto, moderado ou baixo (RAMMSTEDT, 2007).

É importante apregoar que essa teoria passa a ser fortemente utilizada na área de finanças, de acordo com Pompian e Longo (2004). Tais autores, ao fazer uso deste modelo, observaram uma tendência comportamental mais confiante, irrealista e otimista por parte dos indivíduos que são mais sociáveis, levando-os a cometer mais vieses de julgamento na fase de decisões de investimentos.

Em outra vertente, Parsaeimehr, Rezaei e Sedera (2013) com seu trabalho, cujo resultado evidencia que os indivíduos menos sociáveis dão mais importância para as informações financeiras na fase de tomada de decisão de investimento e as mais sociáveis sendo mais impulsivas.

Coube a Conscilly, Iyer e Howeel (2012) utilizarem os traços de personalidade e valores materiais para verificar a gestão de dinheiro para compras compulsivas, dividas e poupança. Os resultados de seus trabalhos sugerem que os indivíduos com maior grau de consciência gerenciam mais o seu dinheiro, dado que suas atitudes financeiras são positivas, tendo então uma orientação positiva voltada para o futuro.

Feitas tais considerações, este trabalho procura fazer uma conjunção trina entre risco, personalidade e a tomada de decisões pela ótica das finanças comportamentais. Para tal, um método foi determinado visando captar os efeitos dessas características dos indivíduos no processo decisório, o que será esmiuçado no próximo tópico, a Metodologia.

\section{Metodologia}

Para alcançar o objetivo central deste trabalho foi realizada uma pesquisa de campo, que tende a "observar e coletar os dados diretamente no próprio local em que se deu o fato em estudo, ca- 
racterizando-se pelo contato direto com o mesmo, sem interferência do pesquisador, pois os dados são observados e coletados tal como ocorrem espontaneamente" (LAKATOS; MARCONI, 1996, p. 75). A partir da observação de fenômenos, exatamente como estes ocorrem na realidade, pode-se coletar dados, analisá-los e interpretá-los, tendo como subsídio uma fundamentação teórica robusta, para explicar o problema de pesquisa (BARROS; FELIPE, 2015).

Desse modo, esta pesquisa reúne aspectos exploratórios e experimentais (MACEDO, 2012). A partir do objetivo principal de entender o processo de tomada de decisão dos agentes e identificar a existência de perfis de risco, observando neste contexto se a personalidade do agente apresentaria vieses de decisão, com base na Teoria do Prospecto, este estudo foi conduzido.

Para este efeito, foram aplicados questionários estruturados em estudantes do nível de graduação e pós-graduados dos estados de São Paulo e Minas Gerais, de diferentes universidades e cursos, totalizando uma amostra de 211 pessoas. Os questionários foram mantidos online pela ferramenta Google Formulários, no período de 18 de fevereiro à 28 de fevereiro 2019. A posteriori, os dados foram tabulados e analisados para evidenciar a presença de vieses cognitivos, assim como para compreender o perfil de personalidade dos respondentes.

Com esta finalidade principal, o questionário aplicado foi elaborado com três partes, a saber: i) na primeira parte, por meio de perguntas relacionadas a gênero, idade, área de atuação e grau de instrução, visou-se captar o perfil do agente tomador de decisão; ii) a segunda parte teve como meta primordial coletar informações sobre os traços de personalidade de cada indivíduo; e, por fim, iii) a terceira parte foi formulada para investigar a presença de vieses comportamentais, onde são propostas quatro perguntas básicas, afinadas com as teorias de finanças nesta área.

Em face disso, o questionário utiliza-se de múltiplas escolhas na primeira e terceira parte, já na segunda faz-se uso de uma escala de Likert de 5 pontos. A descrição das dimensões e características dos traços de personalidade utilizadas no trabalho são apresentadas no Quadro 2 abaixo. Vale notar que, nesta segunda parte do instrumento de pesquisa, cada uma das questões é avaliada em função da escala Likert de 5 pontos, onde " 1 " seria discorda veementemente; 
"2" discorda um pouco; "3" seria não discorda e nem concorda; "4" concorda um pouco e, "5" concorda veementemente. Dessa maneira, as alternativas 1 e 2 satisfazem a dimensão de abertura, a 3 e 4 à consciencialidade, 5 e 6 à afabilidade, 7 e 8 à estabilidade e, 9 e 10 à extroversão - observando, principalmente, os critérios de Alport e Odbert (1936), Goldeberg (1971), Rammsted (2007), e Borghans et al. (2008).

\section{Quadro 2: Dimensões e Características da Personalidade}

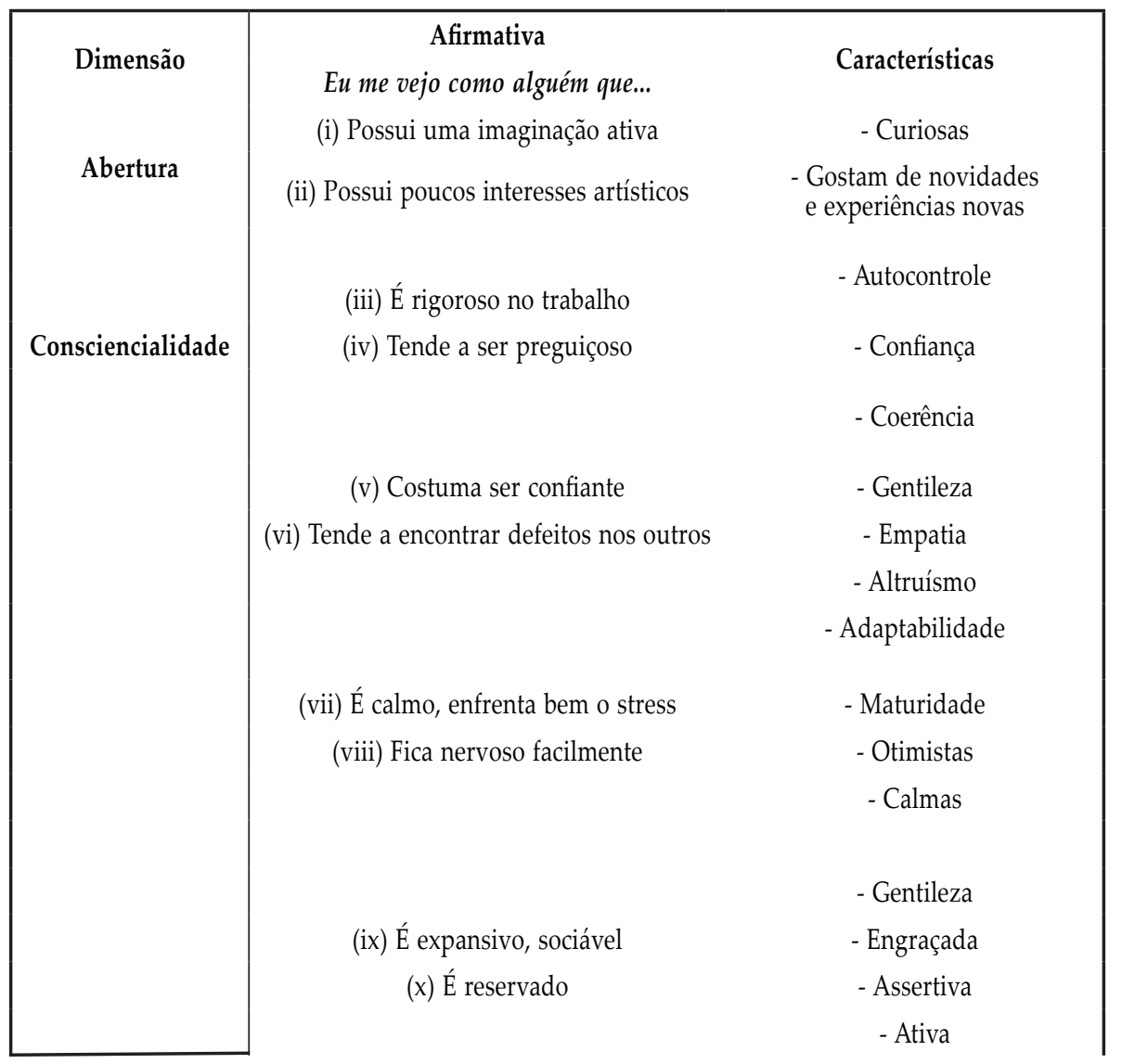

Fonte: Adaptado de Rammsted, 2007. 
Para qualificar o agente quanto ao perfil utilizou-se de uma soma simples, subtraindo o resultado das afirmativas par do resultado das afirmativas ímpar nas questões propostas. Por isso, a pontuação varia entre -4 (evidenciando um traço muito baixo) a +4 (evidenciando um traço forte), e 0 (zero) é aproximadamente a média. Assim, em cada dimensão os indivíduos foram classificados de acordo com as características entre baixa ( -2 ou menos), moderada $(-1$ e +1$)$ e alta (+2 ou mais).

A título de exemplificação, considere que o indivíduo que assinala "concordo pouco" com a questão "Eu me vejo como alguém que possui uma imaginação ativa" deve ter assinalado 4 na afirmativa 1 (ímpar), e se "discorda pouco" com a questão "Eu me vejo como alguém que possui poucos interesses artísticos" ele deve ter assinalado 2 na alternativa 2 (par). Então, neste caso, 4 (na questão ímpar), menos 2 (na questão par) é igual a +2 , o que demonstraria alto grau de abertura.

No que tange à terceira parte do questionário estruturado, o objetivo foi observar os vieses da decisão. Para tal, quatro questões foram delineadas, a saber: a questão 1 se dá pelas perguntas 15 e 16, a questão 2 se dá pela pergunta 17, questão 3 se dá pelas perguntas 18 e 19 e a questão 4 é captada pela pergunta 20, vide Quadro 3 adiante:

Para o primeiro viés (enquadramento) foram feitas duas questões, cada uma de múltipla opção de escolha (A ou B; C ou D), onde as opções A e C; e B e D eram iguais, porém apresentadas de forma diferente (descritas de forma positiva e negativa). O que se tem por objetivo nessas questões era analisar o princípio da invariância, ou seja, se o agente escolher A e C, ou B e D, ele estará agindo de forma racional e assim mantém o princípio da invariância, caso contrário, o mesmo estará alterando sua escolha, mostrando então a irracionalidade de decisão.

Em relação ao segundo viés (concepções da probabilidade), tem-se por objetivo analisar a ótica da representatividade. A resposta correta é a opção A, dado que a probabilidade não se altera quando outro evento já ocorreu (independência de eventos aleatórios). No terceiro viés (enquadramento) é utilizado um método semelhante ao do primeiro viés, porém aqui as alternativas são expostas como 
ganhos e perdas, assim é possível analisar a aversão ao risco, se o agente preferir A e D ou B e C, o mesmo apresentará viés de escolha dado que se comporta de forma diferente quando as opções são descritas em forma monetária.

\section{Quadro 3: Descrição das Questões de Personalidade}

\begin{tabular}{|c|c|c|}
\hline Questão & Viés & Descrição \\
\hline Q1 & $\begin{array}{l}\text { Enquadramento } \\
\text { (Princípio da Inva- } \\
\text { riância) }\end{array}$ & $\begin{array}{l}\text { Opções que envolvem risco são caracterizadas por seus possíveis } \\
\text { resultados e pelas respectivas probabilidades. Todavia, a mesma } \\
\text { opção pode ser descrita ou enquadrada de forma diferente. Se } \\
\text { existir variação nas preferências (inconsistência) ocorre violação } \\
\text { e a decisão não é racional. }\end{array}$ \\
\hline Q2 & $\begin{array}{l}\text { Representatividade } \\
\text { e Disponibilidade } \\
\text { (Concepção de } \\
\text { Probabilidade) }\end{array}$ & $\begin{array}{l}\text { I } \\
\text { Indivíduos ignoram a independência de eventos múltiplos alea- } \\
\text { tórios e, ao invés de buscarem eventos mais aleatórios, utilizam } \\
\text { erroneamente a heurística da representatividade definido por } \\
\text { opções pouco prováveis. }\end{array}$ \\
\hline Q3 & Enquadramento & $\begin{array}{c}\text { As opções estão descritas ou enquadradas em termos de ganho } \\
\text { e perda. Para quem escolhe o ganho certo é avesso ao risco e } \\
\text { quem escolhe a perda certa é atraído pelo risco. Na tomada de } \\
\text { decisão racional não há diferença entre o campo dos ganhos e } \\
\text { das perdas. }\end{array}$ \\
\hline Q4 & $\begin{array}{l}\text { Representatividade } \\
\text { e Disponibilidade } \\
\text { (Falácia da Con- } \\
\text { junção) }\end{array}$ & $\begin{array}{l}\text { Indivíduos, normalmente, avaliam que uma conjunção de dois } \\
\text { eventos (caixa de banco E feminista) seja mais provável de ocor- } \\
\text { rer do que um evento (caixa de banco). Nesse caso, a lógica da } \\
\text { representatividade (similaridade a estereótipos) supera a lógica } \\
\text { da probabilidade. }\end{array}$ \\
\hline
\end{tabular}

Fonte: Adaptado de Tversky e Kahneman (1974)

Levando em consideração o quarto e último viés (falácia da conjunção), pode-se verificar, por meio de uma questão que julga a probabilidade de ocorrência, a lógica da probabilidade e da representatividade, em que pela lei da probabilidade a conjunção de dois eventos não pode ser mais provável que um dos eventos, como na 
questão apresentada (caixa de banco e feminista) ser mais provável de ocorrer que um evento (caixa de banco ou feminista). Dessa feita, a ocorrência da deste viés mostra que a lógica da representatividade (similaridade e estereótipos) supera a lógica da probabilidade e assim os indivíduos cometem uma violação ou sofrem a falácia da conjunção.

Das sete alternativas apresentadas na questão, apenas a " $\mathrm{C}$ ", " $E$ " e "G" eram significativas, as demais servem para apoio na tomada de decisão. Então, a probabilidade de "G" acontecer deveria ser menor do que " $C$ " e " $E$ " ocorrerem, dado que " $G$ " representa a ocorrência de " $\mathrm{C}$ " e " $\mathrm{D}$ ". Após tabular tais resultados, faz-se mister analisar, portanto, a conjunção das três questões principais: perfil do agente, características de personalidade e tomada de decisões à luz da teoria de finanças comportamentais, o que será esmiuçado na análise de resultados adiante.

\section{ANÁlise de RESUlTAdos}

De acordo com a Teoria do Prospecto de Kahneman e Tversky (1979), os indivíduos violam sistematicamente a premissa da Teoria da Utilidade Esperada, sofrendo principalmente do efeito disposição, onde os indivíduos apresentam um comportamento de aversão a risco para ganhos e propenso ao risco para perdas. Assim, começou-se analisando o perfil dos indivíduos que compõem a amostra desta pesquisa. Ao classificar o perfil dos indivíduos, nota-se os respondentes tratados na pesquisa tem um perfil mais jovem, sendo que a faixa etária vai, no máximo, até 32 anos, sendo comum o fácil acesso a informação desses indivíduos. Nota-se que $26 \%$ tem até 32 anos, $40 \%$ até 27 anos e 34\% até 22 anos.

Ademais, dos 211 entrevistados a proporção entre os sexos masculino e feminino foi de 50\%. Já para o grau de instrução dos indivíduos, o Gráfico 1 abaixo demonstra que a proporção de indivíduos que ao menos estão ingressadas no ensino superior corresponde a de $58 \%$ dos entrevistados, sendo a maior área de formação o campo de ciências exatas, que conta com $41,5 \%$ dos participantes, $25 \%$ na área das ciências sociais, 22,6\% estão inseridos na área de ciências humanas, e 10,9\% nas ciências agrárias. 


\section{Gráfico 1: Grau de Instrução dos Respondentes}

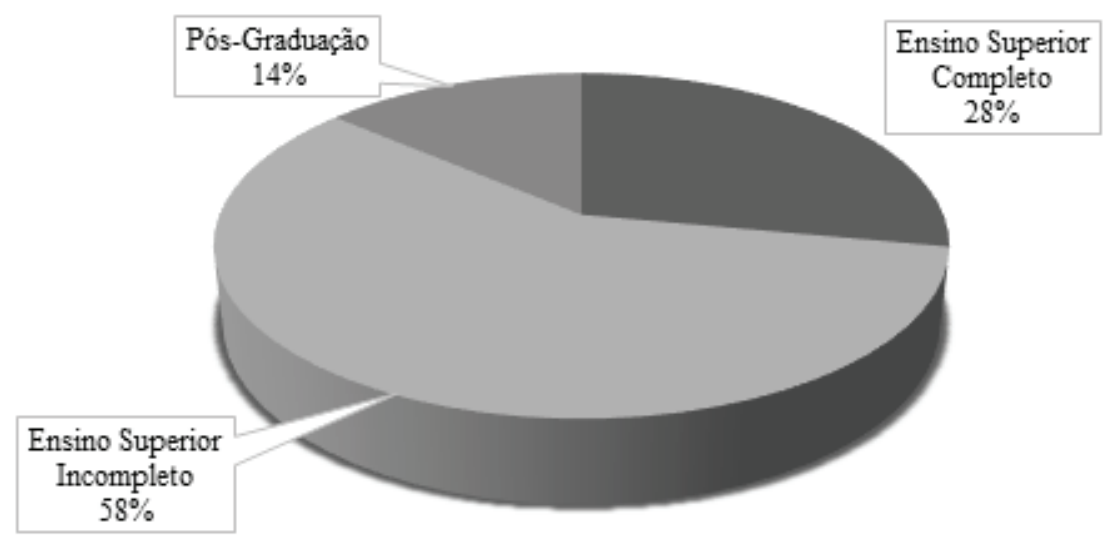

Fonte: Resultados da Pesquisa.

Os resultados da questão 15, no tratam da invariância (e devidamente expresso no Quadro 3), sinalizam que $46,2 \%$ dos indivíduos optaram pela opção A. Porém, na questão 16, 59,9\% dos indivíduos optaram pela opção C, evidenciando que 13,7\% dos indivíduos estão demonstrando a irracionalidade de decisão, onde violaram o princípio da invariância, alterando suas escolhas diante das opções. Dessa maneira, ante os resultados obtidos nas questões 15 e 16 do questionário, pode-se perceber a presença do Efeito Reflexão conforme a Teoria do Prospecto (KAHNEMAN; TVERSKY, 1979), que apregoa que a tomada de decisão pode ser influenciada por valores e expectativas dos indivíduos, bem como pela maneira como as mesmas são apresentadas, sendo com palavras ou números, causando impacto considerável no processo decisório e conduzindo a diferentes decisões.

Para o segundo viés (concepção errôneas da probabilidade), a questão tinha por objetivo evidenciar a ótica da representatividade. Como aponta Shefrin (2000), tal ótica nos mostra que uma probabilidade não se altera quando outro evento já ocorreu, assim os indivíduos são afetados pela ótica, pois ignoram tal fato. Sendo a resposta A considerada correta, verificou-se que apenas $21,2 \%$ dos indivíduos analisaram de forma correta a questão, mostrando que 
$78,8 \%$ foram influenciados pela ótica da representatividade, como pode-se ver no Gráfico 2.

Gráfico 2: Vieses da Teoria do Prospecto, captados pela Questão 17 do Questionário.

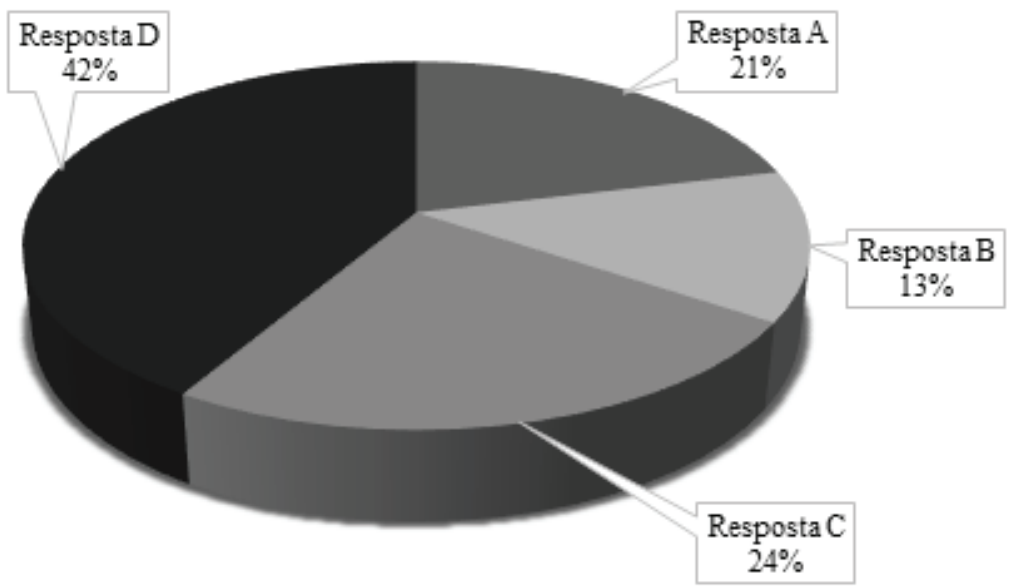

Fonte: Resultados da Pesquisa.

Em relação ao terceiro viés (enquadramento), que é semelhante ao princípio do primeiro viés, mas com alternativas expostas em forma de ganho ou perda monetárias. Destarte, na questão 18, $68,4 \%$ dos indivíduos escolheram a opção A, optando pelo ganho certo, sendo, portanto, avessos ao risco. Já para a questão 19, apenas $20,8 \%$ dos indivíduos escolheram a opção A, mostrando que quando a questão é apresentada em termos de perda, os mesmos agem de forma irracional e tendem a ser propensas a correr riscos. Logo, 47,6\% dos indivíduos foram influenciados por tal viés. Isto confirma um pilar importante das finanças comportamentais, em que o prazer do ganho é menor que a dor da perda, quando um agente está de face das mesmas probabilidades de ganho ou perda.

Para o ultimo viés, designado falácia da conjunção, como discutido por Baldo e Knupp (2018), a lógica da similaridade e estereótipos supera a lógica da probabilidade, evidenciando que os indivíduos foram influenciados pela lógica da representatividade e sofreram pela falácia da conjunção, o que foi possível observar 
em $19,4 \%$ dos indivíduos que violaram a lei da probabilidade ao escolherem a opção de que a conjunção de dois eventos (ser caixa de banco e feminista) fosse maior do que o evento isolado (ser feminista). Nesta perspectiva, vale notar que Baldo e Knupp (2018), em pesquisa conduzida recentemente, chegaram a resultados diferentes, o que poderia estar relacionado com o perfil dos participantes da pesquisa, visto que a maioria eram estudantes de pós-graduação na linha de negócios, o que pode sugerir que eles tenham recebido em sua educação um treinamento que os torne menos suscetíveis a esses vieses.

Assim o viés "concepções errôneas da probabilidade" (Questão 17) ocorreu com maior frequência, abrangendo $62,4 \%$ dos estudantes de pós-graduação. $\mathrm{O}$ viés de enquadramento em termos de ganho e perda (Questão 18 e 19) se manifestou em 57,9\% dos participantes e a falácia da conjunção (Questão 20) foi notada em 56,7\% dos estudantes. Por outro lado, apenas $17,4 \%$ dos participantes foram afetados pelo viés do enquadramento (Questão 15 e 16).

Ademais, para os traços de personalidade, embasados no Quadro 2 da plataforma teórica deste trabalho, nota-se a predominância de extroversão, sendo então o traço mais comum $(28,9 \%)$ o que caracteriza as pessoas como mais assertivas, ativas e gentis. Tal resultado foi superior aos traços de abertura (25,1\%), quando os indivíduos mostram serem curiosos e gostam de novas experiências; seguido por consciencialidade $(18,5 \%)$, em que os indivíduos são mais confiantes e coerentes, tendo um maior autocontrole; estabilidade $(18 \%)$ comum a pessoas serem maduras, calmas e adaptáveis; e socialização $(9,5 \%)$, perfil de indivíduos com cariz mais altruísta e empático.

Analisando os resultados obtidos, tem-se que quase 1/3 dos indivíduos se caracterizam na dimensão de extroversão, o que enfatiza aquelas pessoas que tendem a ser mais gentis, engraçadas, ativas e assertivas. Observa-se também que, aproximadamente, 1/4 dos indivíduos se enquadram na dimensão de abertura como pessoas mais curiosas, tendendo a gostar de novas experiências, sendo assim pessoas que tendem a agir por sentimentos. Por outro lado, tem-se que apenas 9,5\% dos indivíduos se enquadram na dimensão de socialização, sendo assim mostrando que são pessoas com mais empatia, 
cordialidade e gentileza, porém ainda sim se mostrando altruístas. Todos estes resultados estão amalgamados no Gráfico 3 a seguir:

\section{Gráfico 3: Traços de Personalidade dos Respondentes.}

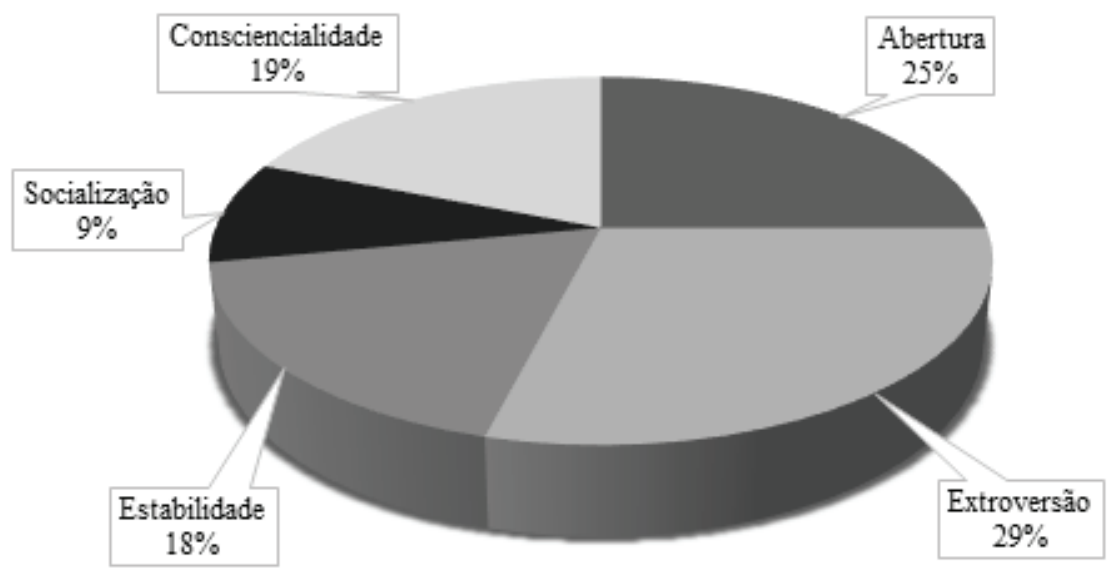

Fonte: Resultados da Pesquisa.

Já no estudo desenvolvido por Baldo e Knupp (2018), os perfis de personalidade se se destacaram foram o de consciencialidade $(51,1 \%)$ e o de abertura $(46,6 \%)$, indicando que a maioria dos participantes eram indivíduos curiosos e que gostam de novidades, pessoas estas confiáveis e coerentes.

Ao relacionar o perfil de personalidade dos indivíduos e os vieses na tomada de decisão foi possível observar algumas relações estatisticamente positivas. Dessa feita, infere-se que indivíduos com nível mais elevado de consciencialidade apresentaram relação com a heurística da representatividade (Questão 17) e com o viés do enquadramento (Questão 18 e 19). Sem embargo, os indivíduos com alto traço de autocontrole e confiança tendem a utilizar a heurística da representatividade em suas decisões.

Em complemento, fora realizado também um cálculo de correlação de Pearson, que possibilita verificar a existência de relação entre os traços de personalidade e as violações apresentadas nas questões respondidas. O Coeficiente de Pearson mede o grau da 
correlação entre duas variáveis, assumindo valores de -1 e 1, onde 1 seria uma correlação perfeita e positiva entre duas variáveis, o que nos mostra que uma tem muito impacto sobre a outra, assim como -1 nos mostra uma correlação negativa e perfeita, evidenciando que não dependem linearmente uma da outra, porém pode se existir dependência não linear.

Pela Tabela 1, nota-se que a correlação analisada apresenta relações negativas e positivas. Porém, somente as questões 2 e 3 mostram uma relação positiva com os traços de personalidade.

Tabela 1 - Correlação entre questões escolhidas e traços de personalidade

\begin{tabular}{lccc}
\hline & Questão 1 & Questão 2 & Questão 3 \\
Abertura & 0,00452473 & 0,06852537 & $-0,0382582$ \\
Conscienalidade & $-0,00452473$ & $-0,03940384$ & $-0,0007221$ \\
Estabilidade & $-0,01047303$ & 0,05421557 & 0,1764013 \\
Socialização & $-0,09724620$ & 0,00885090 & 0,0835778 \\
Extroversão & $-0,11900724$ & $-0,09933869$ & 0,0842793 \\
\hline
\end{tabular}

Fonte: Resultados da Pesquisa.

Vale apregoar que as questões 2 e 3 estão relacionadas positivamente com os perfis de estabilidade e socialização, mas sendo significativas somente para a dimensão de estabilidade, mostrando que os indivíduos da amostra são calmos, maduros, altruístas e empáticos, o que tende a tal tipo de comportamento pelas características de seu perfil. Já na questão 3, temos uma relação positiva para os traços de consciencialidade, estabilidade e socialização, demonstrando então que quanto maior tal traço maior a probabilidade de ocorrência do efeito enquadramento nos indivíduos desta pesquisa, tendo então por perfil pessoas ativas, maduras, empáticas e altruístas. Para a Questão 2, tem-se uma relação positiva para os traços de abertura, estabilidade e socialização, evidenciando então que tendo então o perfil de pessoas que gostam de novas experiências, calmas, empáticas e altruístas.

Em face dos resultados apresentados, faz-se mister asseverar que os outros traços de personalidade não apresentaram relações 
significativas para com os vieses analisados nesta pesquisa. Neste vértice de análise, assume-se que os perfis de estabilidade e socialização não tiveram relação positiva ou negativa, estatisticamente significante, com percepções errôneas da probabilidade, enquadramento e falácia da conjunção. Tais evidências indicam, em consonância com a literatura, que há uma relação estatisticamente significante entre determinados tipos de personalidade e a disponibilidade para tomar graus distintos de risco, isto é, características psicológicas e comportamentais podem impactar diretamente a decisão dos indivíduos, sendo este, portanto, o foco central das investigações científicas em economia e finanças comportamentais.

\section{CoNSIDERAÇões Finais}

Este artigo tencionou estudar os perfis de personalidade pela esfera econômica, adentrando em uma nova área de estudos, que tem sido fonte de novas proposições teóricas e empíricas. Como foi disposto no referencial teórico que baliza este trabalho, a personalidade poderia afetar o risco assumido pelos agentes no processo de tomada de decisão, sendo este estudo uma proposta de trabalhar com estes temas conexos pertencentes ao vasto campo das finanças comportamentais.

Por meio de uma revisão de conceitos e definições relacionadas às Finanças Comportamentais e da aplicação da pesquisa de Big-Five, verificou-se que os indivíduos utilizam uma série de fatores resultantes do uso de vieses cognitivos e emocionais na tomada de decisão, pois existem evidências de que os indivíduos são limitados e podem cometer erros sistemáticos e não-aleatórios, como propunha a Hipótese dos Mercados Eficientes, tomando decisões nem sempre de forma racional.

Destarte, mapear características individuais que levam a ocorrência de vieses cognitivos ajuda a entender quais aspectos pessoais que influenciam no processo de tomada de decisão. Por isso, compreender como os indivíduos realizam suas escolhas é um dos pontos de interesse das ciências econômicas e das finanças, evidenciando a fundamental importância de ampliar os estudos que abordem aqueles elementos que levam os agentes a optar por alternativas que não sejam ótimas. 
Neste diapasão, este artigo consolidou um esforço neste sentido, mas os dados obtidos nesta pesquisa não podem ser generalizados, dado que a amostra fora não-probabilística. Apesar disso, conclusões importantes foram observadas e podem fomentar estudos futuros. Em suma, os resultados apontam a influência dos vieses "concepções errôneas da probabilidade" e "enquadramento" no ato decisório, fazendo com que os indivíduos não escolham de forma racional e ótima. Ademais, quando a questão é colocada em forma monetária, torna-se evidente que os indivíduos são mais propensos ao risco na perda e mais seguros quando estão pela ótica do ganho.

Com relação a traços de personalidade, os perfis que se destacaram foram os de extroversão e abertura, indicando que maioria dos indivíduos da amostra tem traços de pessoas mais ativas, criativas, curiosas e que gostam de novas experiências, o que nos leva a entender certa propensão ao risco. Vale notar que, pelo fato de os respondentes serem jovens, eles assumem maiores graus de risco, o que é evidenciado pelas questões de enquadramento. Nota-se também que indivíduos com maior grau de estabilidade e socialização tendem a apresentar uma relação positiva com a heurística da representatividade na tomada de decisão, evidenciando a existência de vieses cognitivos como o efeito certeza e reflexo.

Em contrapartida, nas situações em que os indivíduos têm seus perfis de personalidade associados a características mais altruístas, empáticas, assertivas, ativas e emotivas, há, em concordância com a literatura, maior envolvimento com o mundo externo através da companhia de outras pessoas, o que poderia tornar tais indivíduos mais propensos a sofrerem com vieses cognitivos. Por fim, os outros perfis de personalidade não mostraram relação significante com os vieses analisados nesta pesquisa, o que poderia sugerir que esses indivíduos foram aqueles que tomaram decisões de formas mais racionais.

Observados os resultados alcançados neste artigo, sugere-se para pesquisas futuras a reaplicação dos questionários em uma amostra maior, a fim de confirmar os resultados aqui obtidos aqui. Além disso, pode-se adicionar outras perguntas ao questionário visando aprimorar o processo de análise das dimensões de personalidade. Outra proposta seria envolver outras regiões brasileiras, o que permitiria uma análise mais plural e comparada. 


\section{REFERÊNCIAS}

ANI, N.C.; ÖZARI, C. Behavioral Finance: Investors Psychology. Journal of Economics and Finance, 11, 2020.

ANTONY, A. Behavioral finance and portfolio management: Review of theory and literature. Journal of Public Affairs, 20, (1), 2019.

ÁVILA, L. A. C.; OLIVEIRA, A. S.; AVILA, J. R. M. S.; MALAQUIAS, R. F. Behavioral biases in investors' decision: studies review from 2006-2015. Revista de Gestão, Finanças e Contabilidade, 6(2), 112-131, 2016.

BALDO, D. F.; KNUPP, P.S. Behavioral finance: the relationship between persolanality traces and behavioral biases. BASE - Revista de Admnistração e Contabilidade da Usiminas, 2018.

BARBERIS, N. Thirty years of prospect theory in economics: a review and assessment. National Bureau of Economic Research, 2012.

BARROS, T.S.; FELIPE, I.S. Teoria do prospecto: evidencias aplicadas em finanças comportamentais. Revista Adm. FACES Journal, v.14, n.4, p.75-95, 2015.

BAZERMAN, M.H. Processo Decisório. 5. ed. Rio de Janeiro: Campus, 2004.

BORGHANS, L.; DUCKWORTH, A.L.; HECKMAN, J.J.; WEEL, B.T. The economics and psychology of personality traits. Journal of Human Resources, v. 43, n. 4, p. 972-1059, 2008.

BRENNER, L.; MEYLL, T. Robo-advisors: A substitute for human financial advice?. Journal of Behavioral and Experimental Finance, Volume 25, March, 2020.

CARDOSO, R.L.; ALVARENGA, T.K.; OYADOMARI, J.C.T. Interferência das emoções nas decisões e percepções de risco: um ensaio sobre as pesquisas nas áreas de finanças, contabilidade e gestão. In Conferência Internacional sobre Sistemas de Informação e Gestão de Tecnologia. São Paulo, SP/Brasil: FEA-USP, 2012.

CONSCILLY, G; IYER, R; HOWEEL, R.T. The Big Five personality traits, material values, and financial well-being of self-described money managers. Journal of Economic Psychology, 33:1129-1142, 2012.

CORTES, F.M. Finanças Comportamentais: Uma Aplicação da Teoria do Prospecto na Tomada de Decisão de Investidores no Brasil. Tese de Doutorado. Rio de Janeiro: Puc Rio, 2009.

FRANCESCHINI, C. Introdução a finanças comportamentais. In: Ávila; F.; Bianchi, M. Guia de Economia Comportamental e Experimental. 1aㅡ ed., São Paulo, Economia Comportamental. org, p. 176-489, 2015.

FRIEDMAN, H.S.; SCHUSTACK, M.W. Teorias da Personalidade: da teoria clássica à pesquisa moderna. São Paulo: Pratice Hall, 2004.

GALDÃO, A.; FAMÁ, R. A Influência Das Teorias Do Risco, Da Alavancagem E Da Utilidade Nas Decisões Dos Investidores E Administradores. Anais... iii Semead. São Paulo: Fea /Usp, 1998.

GOLDBERG, L. A historical survey of personality scales and inventories. In Advances in Psychological Assessment, ed. Paul McReynolds. CA: Science and Behavior Books, 1971. 
GONÇALVES, A.C.P.; LIMA, R.A.S; MATESCO, V.R. Economia Aplicada. Rio de Janeiro: FGV, 2008.

HALFELD, M.T.; LEITÃO, F.F. Finanças Comportamentais: Aplicações No Contexto Brasileiro. Revista de Administração de Empresas, v.41, n.2, p. 64-71, 2001.

KAHNEMAN, D.; TVERSKY, A. Prospect Theory: An Analysis Of Decision Under Risk. Econometrica, 47, p. 263-292, 1979.

KEYNES, J.M. General Theory of Employment, Interest and Money. London: Palgrave Macmillan, 1936.

KIMURA, H. Finanças Comportamentais e o estudo de reações do mercado de capitais brasileiro. Tese (Doutorado) - Faculdade de Economia, Administração e Contabilidade da Universidade de São Paulo, São Paulo, 2002.

KÖNIGSTORFER, F.; THALMANN, S. Applications of Artificial Intelligence in commercial banks - A research agenda for behavioral finance. Journal of Behavioral and Experimental Finance, v. 27, 2020.

LAKATOS, E.; MARCONI, M. A. Metodologia Científica. São Paulo: Atlas, 1996.

LEGESSE, T.S.; GUO, H. Does firm efficiency matter for debt financing decisions? Evidence from the biggest manufacturing countries. Journal of Applied Economics, vol 23, pp.106128. 09 Jan, 2020.

LEVY, H.; WIENER, Z. Prospect and utility theory: Temporay versus permanente atitude toward risk. Journal of Economics and Business, v.6, p1-23, 2013.

LI, Y.; YANG, L. Prospect theory, the disposition effect, and asset prices. Journal Of Fiancial Economics, v. 107, n.3, p. 715-739, 2013.

LINTNER, J. Behavioral finance: why investors make bad decisions. The Planner, v. 13, n. 1, p. 7-8, 1998.

LOBÃO, J. F. Finanças Comportamentais: Quando A Economia Encontra A Psicologia. Coimbra: Conjuntura Actual Editora, 2012.

MACEDO JR., J.S. Teoria Do Prospecto: Uma Investigação Utilizando Simulação De Investimentos. Tese (Doutorado Em Engenharia De Produção) - Universidade Federal De Santa Catarina - Ufsc, Florianópolis, 2003.

MILANEZ, D.Y. Finanças Comportamentais No Brasil. Dissertação (Mestrado Em Economia) - Faculdade De Economia, Administração E Contabilidade, Universidade De São Paulo, 2003.

MINETO, C.A.L. Percepção Ao Risco E Efeito Disposição: Uma Análise Experimental Da Teoria Dos Prospectos. 2005. Tese De Doutorado. Ufsc. Universidade Federal De Santa Catarina, Florianópolis, 2005.

NUNES, F.S. Finanças comportamentais: uma comparação entre grupos de estudantes com foco no principio de aversão a perda. UFRS, Rio Grande do Sul, 2017. 
PARSAEIMEHR, M.; REZAEI, F.; SEDERA, D. Personality type of investors and perception of financial information to make decisions. Asian Economic and Financial Review, 3(3):283293, 2013.

PAYNE, J.; BETTMAN, J.; JOHNSON, E. Behavioral decision research: a construtive processing perspective. Annual Review of Psychology, 1992

POMPIAN, M.M.; LONGO, J.M. A new paradigm for practical application of behavioral finance: Creating investment programs based on personality type and gender to produce better investment outcomes. The Journal of Wealth Management, 2004.

PONDÉ, J. L. Racionalidade, incomensurabilidade e história: aprendendo com um diálogo entre as obras de HA Simon e TS Kuhn [Discussion Paper]. Instituto de Economia, Universidade Federal do Rio de Janeiro, 2014.

RAMMSTEDT, B.A.; JOHN, O.P. Measuring personality in one minute or less: A 10-item short version of the Big Five Inventory in English and German. Journal of Research in Personality, 2007.

SCHRAND, C.; ZECHMAN, S. Executive overconfidence and the splippery slope to financial misreporting. Journal of Accounting and Economics, v. 53, n. 1, p. 311-329, 2012.

SHEFRIN, H. The Behavioral Paradigm Shift. (2015). RAE (Revista de Administração de Empresas), vol.55, n.1, pp. 95-98, 2015.

SHERIF, M. The impact of Coronavirus (COVID-19) outbreak on faith-based investments: An original analysis. Journal of Behavioral and Experimental Finance. v. 28, 2020.

SNELBECKER, G. E.; ROSZKOWSKI, M. J.; CUTLER, N. E.. Investors' Risk Tolerance and Return Aspirations, and Financial Advisors' Interpretations: A Conceptual Model and Exploratory Data. Journal of Behavioral Economics, v.19, n.4, p.377-393, 1990.

SOBREIRA, M. S. Aplicação da teoria do prospecto nos bancos brasileiros: agregando valor para a carteira de investimentos de um fundo de pensão. 2007. 69 p. Dissertação (Mestrado) - Curso de Pós-Graduação em Economia, Faculdades Ibmec, Rio de Janeiro, 2007.

STOSIC-MIHAJLOVIC, L. Functioning of financial and capital markets in modern conditions. Journal of Process Management New Technologies, 4(4):30-38. DOI: 10.5937/jouproman4-12134, 4 Oct, 2016.

TALLMAN, I.; GRAY, L. Choices, decisions and problem-solving. Annual Reciew of Sociology. 1990.

THALER, R.; BARBERIS, N. A Survey Of Behavioral Finance. In: Constantinides, G.; Harris, M.; Stulz, R. (Eds.), Handbook Of The Economics Of Finance. New York: North-Holland, 2003.

TOUBIA, O; JOHNSON, E.; EVGENIOU, T.; DELQUIÉ, P. Dynamic experiments for estimating preferences: $\mathrm{Na}$ adaptive method of eliciting time and risk paramentes. Managment Science, v 59, n 3, p. 613-640, 2013.

TVERSKY, A.; KAHNEMAN, D. Rational choice and the framing of decisions. Journal of Business, 1986. 
TVERSKY, A.; KAHNEMAN, D. Judgment under Uncertainty: Heuristics and Biases. Science, New Series, Vol. 185, No. 4157. (Sep. 27), pp. 1124-1131, 1974.

VARDARI, L. The Analysis of Active Portfolio Management in Emerging Markets: Markowitz Modern Portfolio Method. In: Studies on Interdisciplinary Economics and Business - Volume III. Özer ÖZÇELIK (ed.). Peter Lang GmbH, Internationaler Verlag der Wissenschaften. Berlin, 2020.

VENDRAMINE, M. F. M.; NOBRE, F. C.; VIEIRA, A. M. Como enfrentar a Covid-19? O Sol de maio vai nos ajudar? Revista Pensamento Contemporâneo em Administração, v. 15, n. 1, p. 197-211, 2021.

XIAO, J. J. Handbook of Consumer Finance Research. New York: Springer, Science and Business Media, LLC, 2008.

YOSHINAGA, C. E.; RAMALHO, T.B. Finanças comportamentais no Brasil: uma aplicação da teoria da perspectiva em potenciais investidores. Revista Brasileira de Gestão de Negócios, v. 16, n. 53, p. 594-615, 2014.

ZAMBONETTI, M. Tomada de decisão em grupo e individual: uma análise da existência do efeito disposição. Florianópolis, 2009. 73 p. (Trabalho de Conclusão de Curso de Ciências Econômicas) - Universidade Federal de Santa Catarina, Florianópolis, 2009.

ZAJONC, R. Feeling and thinking: preferences need no inferences. American psychologist, 1980.

Recebido em: 19-8-2019

Aprovado em: 22-7-2021

Avaliado pelo sistema double blind review.

Disponível em http://mjs.metodista.br/index.php/roc 